\title{
REVIEW
}

\section{Multiplex biomarkers in blood}

\author{
Veer Bala Gupta', Ramani Sundaram² and Ralph N Martins $1,3,4 *$
}

\begin{abstract}
Advances in the field of blood biomarker discovery will help in identifying Alzheimer's disease in its preclinical stage, allowing treatment to be initiated before irreversible damage occurs. This review discusses some recent past and current approaches being taken by researchers in the field. Individual blood biomarkers have been unsuccessful in defining the disease pathology, progression and thus diagnosis. This directs to the need for discovering a multiplex panel of blood biomarkers as a promising approach with high sensitivity and specificity for early diagnosis. However, it is a great challenge to standardize a worldwide blood biomarker panel due to the innate differences in the population tested, nature of the samples and methods utilised in different studies across the globe. We highlight several issues that result in the lack of reproducibility in this field of research currently faced by researchers. Several important measures are summarized towards the end of the review that can be taken to minimize the variability among various centres.
\end{abstract}

\section{Introduction}

The pathology of Alzheimer's disease (AD) accumulates decades before the clinical symptoms start to appear. Extracellular amyloid deposits and intracellular neurofibrillary tangles are the classic hallmarks of AD. There are well established genetic markers for early onset $\mathrm{AD}$ but more than $95 \%$ of $\mathrm{AD}$ patients suffer from the sporadic form. The aetiology of the sporadic form of $\mathrm{AD}$ has been understood to be multifactorial and is influenced by various genetic, biochemical and environmental factors. Prediction of future pathological cognitive decline in $\mathrm{AD}$ is of critical importance as it would allow

${ }^{*}$ Correspondence: r.martins@ecu.edu.au

${ }^{4}$ Suite 22, Hollywood Medical Centre, 85 Monash Ave, Nedlands, Western Australia, 6009 Australia

Full list of author information is available at the end of the article for current and future prevention and treatment strategies to be initiated when they are likely most effective - and would also have applications in monitoring of medical and lifestyle interventions. It has been demonstrated earlier that $\mathrm{AD}$ biomarkers can detect the disease long before the clinically obvious symptoms appear [1]. A biomarker is objectively measured and evaluated as an indicator of a pathological process or pharmacological response to a therapeutic intervention. The sensitivity, specificity and ease-of-use are the most important factors that ultimately define the diagnostic utility of a biomarker. They are important avenues to disease diagnosis and identifying individuals at risk. Identification of such reliably validated biomarkers has led to the introduction of a diagnostic preclinical phase where the biomarkers are present in asymptomatic individuals [2].

Whilst there have been major advances in neuroimaging, particularly amyloid beta $(A \beta)$ imaging, its use as a routine diagnostic test is cost prohibitive. As such, attention has switched to the periphery and readily accessible biological material for AD biomarker research. Over recent years, cerebrospinal fluid (CSF) has been the major focus of proteomic biomarker discovery studies; however, CSF collection is a highly invasive procedure that is difficult to implement in the clinical routine and in clinical trials. Therefore, a strong interest exists for less invasive diagnostic approaches for $\mathrm{AD}$, such as bloodderived biomarkers. An ideal AD blood biomarker (or panel) should represent the associated pathological and biochemical changes occurring in the brain. AD blood biomarker research is still at an early stage of development and clinical evaluation before it can be integrated into clinical practice as a key diagnostic tool. The measurement and reliability of these blood biomarkers is limited by the physiology of the blood brain barrier. Moreover, the biomarkers closely associated with disease pathology are found in very low concentrations in blood, which is furthermore compromised by the complex biochemical nature of the fluid [3]. A major limitation of blood biomarker studies is the lack of reproducibility of the results. This review discusses the current knowledge on blood biomarkers in $\mathrm{AD}$, focussing on the multiplex approach with discussion on novel strategies for biomarker discovery. 


\section{Individual blood biomarkers}

The quest for finding biomarkers for AD started with traditional approaches involving a single biomarker, such as $A \beta$ [4-6], but the drawbacks included large inter- and intra-person variability and results were not consistent with the sporadic form of $\mathrm{AD}[7,8]$. The results have been conflicting as $A \beta$ present in plasma is also derived from peripheral tissues, non-neural systems and blood components, thus constantly allowing dynamic interchange of $\mathrm{A} \beta$ between brain and periphery. This might be one of the reasons for failure of anti-amyloid interventions in $\mathrm{AD}$, so there is a need to determine the significance of various sources of $A \beta$ in plasma. In addition, $A \beta$ binds avidly to various plasma proteins and membranes. Several longitudinal and cross-sectional studies on plasma $A \beta 40$ and $A \beta 42$ show wide variations within and among individuals as well $[9,10]$. Several other factors also contribute to the levels of $A \beta$ in plasma, such as diet, medication, stress and circadian rhythm [11].

Lately, many candidate biomarkers have been studied individually, such as apolipoprotein E (ApoE), apoJ, $\alpha-1$ antitrypsin, complement factors, cytokines, apoA-1 and many more [12]. Padovani and colleagues [13] reported altered levels of amyloid precursor protein in $\mathrm{AD}$ patients, showing a reduced ratio of higher to lower molecular weight isoforms. The ratio was associated with disease severity and progression with 80 to $90 \%$ sensitivity and specificity. Our lab reported levels of plasma apoE in $\mathrm{AD}$ in the baseline Australian Imaging Biomarkers Lifestyle (AIBL) cohort, which indicated a strong relationship between apoE levels, $\mathrm{AD}$ and apoE4 status, which is known to be the greatest risk factor for AD [14]. Interestingly, lower levels of apoE in $\mathrm{AD}$ were also observed irrespective of apoE4 genotype, that is, in nonapoE4 allele carriers. Another study [15] comparing plasma and CSF levels of apoE in AD and control subjects showed dependence of plasma apoE levels on apoE genotype. Further, plasma apoE levels did not correlate with CSF apoE levels, but CSF apoE did correlate with CSF A $\beta 42$ levels. This raises the question of validation and interpretation of peripheral biomarkers, whose production and clearance may be relatively independent in the periphery and in the brain.

In addition to protein biomarkers, evidence on the role of cholesterol and cholesterol metabolism in AD pathology indicates that hypercholesterolemia is closely associated with mild cognitive impairment (MCI) and AD $[16,17]$. Studies suggest that lipid lowering agents and statins reduce the risk of $\mathrm{AD}[18,19]$. 24S-Hydroxycholesterol, a cholesterol metabolite, reflects brain homeostasis, that is, the balance between the intra- and extra-cerebral pools of cholesterol [20]. Certain studies have shown significant reduction in levels of $24 \mathrm{~S}$ hydroxycholesterol in plasma [21] while others revealed inconsistent increases of the same compound in plasma [22,23] with weak correlation to CSF levels [24].

AD has a complex pathology involving several molecular pathways, such as amyloid deposition, taupathy, oxidative damage, inflammation and metabolic changes. The markers of underlying pathology in all these pathways can serve as markers for AD. A broad range of markers have been studied extensively in correlation with AD disease pathology, conversion and progression. Growing evidence suggests that oxidation plays a crucial role in $\mathrm{AD}$ pathogenesis. Markers of oxidative damage are found in $\mathrm{AD}$ brain, including protein, lipid and nucleic acid oxidation products [25,26]. Isoprostanes, products of lipid peroxidation, have been associated with $\mathrm{AD}$ in many studies $[27,28]$. Results have been promising with CSF; F2-isoprostanes seem to increase during conversion from MCI to AD [29], closely associated with imaging and memory parameters with good sensitivity and specificity [30]. Results have been inconsistent with regard to levels in plasma as a few studies have reported increased levels [31,32] while others have reported no significant difference $[33,34]$. One possibility for the discrepancies may be the presence of vascular risk factors that can alter the levels of F2-isoprostanes [35]. It is now well proven that inflammation also plays a vital role in AD pathology. Astroctyosis, microgliosis, complement activation and upregulation of acute phase proteins are inflammatory responses elicited by amyloid deposition in brain. Measurement of these markers in blood is unclear as these proteins may not cross the blood brain barrier. These makers include C-reactive protein, IL-1 $\beta$, tumour necrosis factor- $\alpha$, IL-6, IL-6 receptor complex, $\alpha 1$ antichymotrypsin and transforming growth factor- $\beta$, and cytokines such as IL-12, interferon- $\alpha$, and interferon- $\beta$ [36]. Despite a plethora of blood biomarker literature in $\mathrm{AD}$, these are unlikely to be diagnostically sufficient individually as they lack the required sensitivity and specificity to be potential AD biomarkers.

\section{Multiplex approach}

There is a definite need for a holistic approach for standardizing blood biomarkers for AD. It is crucial to understand the relationship between various individual biomarkers and move away from the traditional approach of investigating levels of single candidate biomarkers at a time. Many studies have formulated panels of biomarkers to distinguish between healthy and AD participants and evaluated broad ranges of proteins in different combinations to yield high sensitivity and specificity $[37,38]$. There has been considerable development in the discovery of cost-effective plasma protein biomarkers for AD [39]. In a panel of 120 signalling proteins, 18 proteins had $82 \%$ specificity in differentiating $\mathrm{AD}$ from healthy subjects and predicting the conversion from $\mathrm{MCI}$ to $\mathrm{AD}$ 
[40]. Tuenissen and colleagues [36] evaluated 29 serum biomarkers that can differentiate AD from healthy participants. These included inflammatory biomarkers such as IL-6 and metabolic biomarkers such as cholesterol metabolites, cysteine and homocysteine. Doecke and colleagues [41] reported on AIBL baseline plasma screening of 151 analytes combined with targeted biomarker and clinical pathology data in a total of 961 participants. An initial plasma biomarker panel consisting of 18 biomarkers was identified that distinguishes individuals with $\mathrm{AD}$ from cognitively healthy controls with high sensitivity and specificity. A final signature panel of eight proteins (beta 2 microglobulin, carcinoembryonic antigen, cortisol, epidermal growth factor receptor, IGFBP-2, IL-17, PPY and VCAM-1) was identified that showed increased prediction accuracy when validated in an Alzheimer's Disease Neuroimaging Initiative (ADNI) dataset. A similar study [42] reported on the measured levels of 190 plasma proteins in a total of 600 participants. An initial panel of 17 analytes associated with the diagnosis of very mild dementia/MCI or $\mathrm{AD}$ was identified. Their analysis yielded a set of four plasma analytes (ApoE, B-type natriuretic peptide, $\mathrm{C}$-reactive protein, pancreatic polypeptide) that were consistently associated with the diagnosis of very mild dementia/MCI/AD when validated across the ADNI cohort. A comparison among panels of analytes derived from such similar studies reveals very few common blood biomarkers for AD. Despite having similar analytical platforms and common validation cohorts, there are discrepancies in the numbers of plasma biomarkers identified by these studies. The likely reasons for this could be variation in pre-analytical variable selection, which could lead to differential interaction between analytes of interest, differences in innate characteristics of a cohort based on region and different statistical approaches employed by the different groups.

There are different methods for identifying biomarkers in blood (Table 1); hence, it is important to standardize the methods of generation of proteomic data and the entire workflow. In order to standardize a panel of biomarkers for $\mathrm{AD}$ diagnosis, consensus on protocols and ultrasensitive analytical methods are required through multicentre studies. Proteins in a sample can be separated using two-dimensional polyacrylamide gel electrophoresis or high performance liquid chromatography [43]; surface chromatography by adsorbing proteins to activated surfaces (surface-enhanced or matrix-assisted laser desorption-ionization protein chip array technology) [44]; and peptide ionization procedures for analysis of proteins from gels or protein chips by mass spectroscopy (MS). Each technology has its own advantages and limitations. For example, researchers use two-dimensional gel electrophoresis-MS for plasma biomarker analysis because of its remarkable resolving power, increased sensitivity and high throughput proteome analysis capabilities [37,45], and although this technology is usually accessible to most of the researchers, it is laborious and not applicable for small and hydrophobic peptides. In addition there is a limited dynamic range for quantitative measurement. Recent studies have been exploring liquid chromatography-MS because it requires only small amounts of sample and is highly sensitive. Complex quantification analysis and sensitivity for interfering compounds are the drawbacks for this technique. Surface enhanced laser desorption/ ionization-time of flight MS is a newly introduced protein identification technique with better resolution and quantification and selective capture of proteins under native conditions, although the post-processing is a complex procedure and reproducibility is still problematic. Enzyme-linked immunosorbent assay (ELISA) is one of the major proteomic techniques used worldwide for quantification of proteins but the major disadvantage is the availability of specific antibodies.

\section{Challenges associated with standardization and validation of the results}

Although an overwhelming volume of research has been done in the field of AD blood biomarkers so far, there is a clear lack of reproducibility of the results obtained across different studies. Firstly, differing methods of collection, transport and storage of samples may be one of the reasons for the observed differences. AIBL study protocol involves overnight fasting for the participants; the same is not the case, however, for other well characterized cohorts such as the Texas Alzheimer's Research and Care Consortium (TARCC). Long-term storage of the samples in liquid nitrogen versus $-80^{\circ} \mathrm{C}$ freezer has an impact on the levels of certain protein biomarkers. Secondly, variations among the assay and interpretation methods could be another factor. Changes in the biomarker panel have been observed when alternative methods are used (for example, MS versus ELISA). Thirdly, selection criteria of the cohort could be another important factor. The participants recruited in different studies might be at different stages of disease pathology though the clinical symptoms are still concealed. Standardized neuropsychological assessments across populations to obtain uniformity in recruited cohorts is lacking.

\section{Recommendations and conclusion}

$\mathrm{AD}$ is a multifaceted disease and biomarkers need to be visualized in a broader range that can correlate to the underlying neurodegenerative phenomenon. $\mathrm{As} A D$ is multifactorial, no single biomarker will be able to explain the progression or pathology of AD and hence single biomarker approaches have been unsuccessful in predicting the disease pattern. Proteomics has gained the 
Table 1. Summary of some recent multiplex Alzheimer's disease biomarker studies

\begin{tabular}{lll}
\hline Author & Technique & Biomarkers \\
\hline Doecke et al. [41] & Multiplex panel: Human Discover MAP, version 1.0; RBM & 151 multiplexed analytes \\
Watt et al. [47] & Copper immobilized metal affinity capture and SELDI & Three candidate biomarkers in blood \\
Ray et al. [40] & Filter based, arrayed sandwich-ELISA & Chemokines, growth factors, and inflammation markers \\
Zhang et al. [48] & Multidimensional LC in combination with one- and & Serum-based biomarkers \\
& two-dimensional PAGE & \\
& MALDl and ESI-MS & Inflammatory response mediators \\
& ELISA multiplex platforms & Amyloid beta \\
Henkel et al. [49] & Anion exchange and reverse phase chromatography & 12 high-abundance proteins from plasma \\
Choi et al. [50] & Two-dimensional PAGE, western blot, and MALDI-MS & Fibrinogen gamma chain and alpha1 antitrypsin \\
Lopez et al. [51] & Affinity chromatography, spin columns and MALDI-MS & Pattern of unidentified proteins in serum \\
\hline
\end{tabular}

ESI-MS, electrospray ionization-mass spectrometry; LC, liquid chromatography; MALDI, matrix-assisted laser desorption/ionization; MAP, multi-analyte profiling; RBM, rules based medicine; SELDI, surface enhanced laser desorption/ionization.

interest of researchers as a promising way to decode the biomarker mystery. However, the close interaction of various fields, such as lipidomics, genomics and proteomics, is required to achieve an optimal AD biomarker panel. This kind of 'multi-omic' interdisciplinary approach will strikingly advance further biomarker discovery.

Further, different blood fractions may be appropriate to study particular sets of biomarkers because of the differences in the distribution of blood-based proteins. The source of the biomarker (plasma versus serum) can have a large impact on the observed concentration of some proteins, including the ones of great interest in AD pathophysiology [46]. Platelets are becoming increasingly popular in blood biomarker research because of their homogenous and compartmentalized nature. Both plasma and serum are very heterogenous in nature and have complex and abundant pools of proteins such as albumin and IgG that can potentially interfere in achieving the required sensitivity for the assay.

Researchers tend to use the general term 'AD blood biomarker' for an early $\mathrm{AD}$ diagnosis; however, there exists a huge need to have a separate set of signatures to identify different stages of $\mathrm{AD}$, such as pre-clinical, prodromal and clinical. A unique set of blood analytes is required to successfully predict the conversion of preclinical AD participants and also to differentiate controls from MCI progressors and those who do not progress to further cognitive decline. These sets of biomarkers should then be validated against other established clinical correlates such as the $\mathrm{t}$-tau/A $\beta 42$ ratio from CSF and neuroimaging so that they can be integrated into clinical practice. This will help in the speedy and accurate diagnosis of sporadic AD, should be able to detect disease progression, and have an impact on therapeutic intervention, the classification of different stages of $\mathrm{AD}$ and the differentiation of AD from other dementias.
The following are more selected recommendations for multiplex biomarker researchers. First, there is a need for extensive longitudinal studies with the aim of studying biomarkers along the course of the disease spectrum. The longitudinal change in biomarkers should be examined as a putative biomarker itself, as has been done with cognitive markers. Second, well defined and characterized $\mathrm{AD}$ cohorts need to be established and used for biomarker discovery. Non-AD dementia cohorts should be studied in parallel to determine the overlapping and non-overlapping biomarker profiles between dementia (in general) and AD. Third, variations in biomarker measurements among different labs need to be overcome by establishing a consensus among experts involved in biomarker research - the 'Delphi method. This will facilitate identification of the challenges associated with standardization of the protocols and disparities in techniques. Fourth, multicentre studies such as ADNI and EADNI are needed. These studies should adopt standardized neuropsychological assessments, identical protocols, and uniform methods of analysis and interpretation of data. Fifth, combinations of blood biomarkers, risk factors, imaging, neuropsychological measures and clinical data should be critically evaluated.

The major benefit from a successful multiplex blood biomarker approach in $\mathrm{AD}$ would be to provide an inexpensive and minimally invasive diagnostic test capable of monitoring changes over time and responses to clinical interventions.

This article is part of a series on Peripheral Biomarkers, edited by Douglas Galasko. Other articles in this series can be found at http://alzres.com/series/biomarkers 


\section{Abbreviations}

$A \beta$, amyloid beta; AD, Alzheimer's disease; AIBL, Australian Imaging Biomarkers Lifestyle; apo, apolipoprotein; CSF, cerebrospinal fluid; ELISA, enzyme-linked immunosorbent assay; IL, interleukin; $\mathrm{MCl}$, mild cognitive impairment; MS, mass spectroscopy.

\section{Competing interests}

The authors declare that they have no competing interests.

\section{Acknowledgements}

VBG acknowledges Edith Cowan University for her salary support. RS is currently supported as a visiting scientist by McCusker foundation. Core funding for the AIBL related work mentioned in this manuscript was provided by CSIRO, which was supplemented by "in kind" contributions from study partners. The McCusker Alzheimer's Research Foundation Inc. contributed financial and in kind support to AIBL.

\section{Author details}

'Centre of Excellence for Alzheimer's disease Research \& Care, School of Medical Sciences, Edith Cowan University, Joondalup, WA, 6027 Australia. ${ }^{2}$ Centre for Ageing and Alzheimer's, Nightingales, Bangalore, 560043 India. ${ }^{3}$ Sir James McCusker Alzheimer's Disease Research Unit (Hollywood Private Hospital), Perth, WA, 6009 Australia. ${ }^{4}$ Suite 22, Hollywood Medical Centre, 85 Monash Ave, Nedlands, WA, 6009 Australia.

\section{Published: 25 June 2013}

\section{References}

1. Jack CR Jr, Vemuri P, Wiste HJ, Weigand SD, LesnickTG, Lowe V, Kantarci K, Bernstein MA, Senjem ML, Gunter JL, Boeve BF, Trojanowski JQ, Shaw LM, Aisen PS, Weiner MW, Petersen RC, Knopman DS; Alzheimer's Disease Neuroimaging Initiative: Shapes of the trajectories of 5 major biomarkers of Alzheimer disease. Arch Neurol 2012, 69:856-867.

2. Sperling RA, Aisen PS, Beckett LA, Bennett DA, Craft S, Fagan AM, IwatsuboT, Jack CR Jr, Kaye J, Montine TJ, Park DC, Reiman EM, Rowe CC, Siemers E, Stern Y, Yaffe K, Carrillo MC, Thies B, Morrison-Bogorad M, Wagster MV, Phelps CH: Toward defining the preclinical stages of Alzheimer's disease: recommendations from the National Institute on Aging-Alzheimer's Association workgroups on diagnostic guidelines for Alzheimer's disease. Alzheimers Dement 2011, 7:280-292.

3. Irizarry MC: Biomarkers of Alzheimer disease in plasma. NeuroRx 2004, 1:226-234.

4. Lui JK, Laws SM, Li QX, Villemagne VL, Ames D, Brown B, Bush Al, De Ruyck K, Dromey J, Ellis KA, Faux NG, Foster J, Fowler C, Gupta V, Hudson P, Laughton K, Masters CL, Pertile K, Rembach A, Rimajova M, Rodrigues M, Rowe CC, Rumble R, Szoeke C, Taddei K, Taddei T, Trounson B, Ward V, Martins RN, AIBL Research Group: Plasma amyloid-beta as a biomarker in Alzheimer's disease: the AIBL study of aging. J Alzheimers Dis 2010, 20:1233-1242.

5. Mayeux R, Tang MX, Jacobs DM, Manly J, Bell K, Merchant C, Small SA, Stern Y, Wisniewski HM, Mehta PD: Plasma amyloid beta-peptide 1-42 and incipient Alzheimer's disease. Ann Neurol 1999, 46:412-416.

6. Tamaoka A, Fukushima T, Sawamura N, Ishikawa K, Oguni E, Komatsuzaki Y, Shoji S: Amyloid beta protein in plasma from patients with sporadic Alzheimer's disease. J Neurol Sci 1996, 141:65-68.

7. Assini A, Cammarata S, Vitali A, Colucci M, Giliberto L, Borghi R, Inglese ML, Volpe S, Ratto S, Dagna-Bricarelli F, Baldo C, Argusti A, Odetti P, Piccini A, Tabaton M: Plasma levels of amyloid beta-protein 42 are increased in women with mild cognitive impairment. Neurology 2004, 63:828-831.

8. Fukumoto H, Tennis M, Locascio JJ, Hyman BT, Growdon JH, Irizarry MC: Age but not diagnosis is the main predictor of plasma amyloid beta-protein levels. Arch Neurol 2003, 60:958-964

9. Scheuner D, Eckman C, Jensen M, Song X, Citron M, Suzuki N, Bird TD, Hardy J, Hutton M, Kukull W, Larson E, Levy-Lahad E, Viitanen M, Peskind E, Poorkaj P, Schellenberg G, Tanzi R, Wasco W, Lannfelt L, Selkoe D, Younkin S: Secreted amyloid beta-protein similar to that in the senile plaques of Alzheimer's disease is increased in vivo by the presenilin 1 and 2 and APP mutations linked to familial Alzheimer's disease. Nat Med 1996, 2:864-870.

10. Kosaka T, Imagawa M, Seki K, Arai H, Sasaki H, Tsuji S, Asami-Odaka A, Fukushima T, Imai K, Iwatsubo T: The beta APP717 Alzheimer mutation increases the percentage of plasma amyloid-beta protein ending at A beta42(43). Neurology 1997, 48:741-745.
11. Blasko I, Kemmler G, Krampla W, Jungwirth S, Wichart I, Jellinger K, Tragl KH, Fischer P: Plasma amyloid beta protein 42 in non-demented persons aged 75 years: effects of concomitant medication and medial temporal lobe atrophy. Neurobiol Aging 2005, 26:1135-1143.

12. Davinelli S, Intrieri M, Russo C, Di Costanzo A, Zella D, Bosco P, Scapagnini G: The "Alzheimer's disease signature": potential perspectives for novel biomarkers. Immun Ageing 2011, 8:7.

13. Padovani A, Pastorino L, Borroni B, Colciaghi F, Rozzini L, Monastero R, Perez J, Pettenati C, Mussi M, Parrinello G, Cottini E, Lenzi GL, Trabucchi M, Cattabeni F, Di Luca M: Amyloid precursor protein in platelets: a peripheral marker for the diagnosis of sporadic AD. Neurology 2001, 57:2243-2248.

14. Gupta VB, Laws SM, Villemagne VL, Ames D, Bush Al, Ellis KA, Lui JK, Masters C, Rowe CC, Szoeke C, Taddei K, Martins RN; AIBL Research Group: Plasma apolipoprotein $\mathrm{E}$ and Alzheimer disease risk: the AIBL study of aging. Neurology 2011, 76:1091-1098.

15. Cruchaga C, Kauwe JS, Nowotny P, Bales K, Pickering EH, Mayo K, Bertelsen S, Hinrichs A; Alzheimer's Disease Neuroimaging Initiative, Fagan AM, Holtzman DM, Morris JC, Goate AM: Cerebrospinal fluid APOE levels: an endophenotype for genetic studies for Alzheimer's disease. Hum Mol Genet 2012, 21:4558-4571.

16. Kivipelto M, Helkala EL, Laakso MP, Hanninen T, Hallikainen M, Alhainen K, Soininen $\mathrm{H}$, Tuomilehto J, Nissinen A: Midlife vascular risk factors and Alzheimer's disease in later life: longitudinal, population based study. BMJ 2001, 322:1447-1451.

17. Launer L, White LR, Petrovitch H, Ross GW, Curb JD: Cholesterol and neuropathologic markers of AD: a population-based autopsy study. Neurology 2001, 57:1447-1452.

18. Jick H, Zornberg GL, Jick SS, Seshadri S, Drachman DA: Statins and the risk of dementia. Lancet 2000, 356:1627-1631

19. Rockwood K, Kirkland S, Hogan DB, MacKnight C, Merry H, Verreault R, Wolfson C, McDowell I: Use of lipid-lowering agents, indication bias, and the risk of dementia in community-dwelling elderly people. Arch Neurol 2002, 59:223-227.

20. Bjorkhem I, Cedazo-Minguez A, Leoni V, Meaney S: Oxysterols and neurodegenerative diseases. Mol Aspects Med 2009, 30:171-179.

21. Bretillon L, Siden A, Wahlund LO, Lutjohann D, Minthon L, Crisby M, Hillert J, Groth CG, Diczfalusy U, Bjorkhem I: Plasma levels of 24S-hydroxycholesterol in patients with neurological diseases. Neurosci Lett 2000, 293:87-90.

22. Papassotiropoulos A, Lutjohann D, Bagli M, Locatelli S, Jessen F, Buschfort R, Ptok U, Bjorkhem I, von Bergmann K, Heun R: 24S-hydroxycholesterol in cerebrospinal fluid is elevated in early stages of dementia. J Psychiatr Res 2002, 36:27-32.

23. Schonknecht $P$, Lutjohann D, Pantel J, Bardenheuer H, Hartmann T, von Bergmann K, Beyreuther K, Schroder J: Cerebrospinal fluid 24Shydroxycholesterol is increased in patients with Alzheimer's disease compared to healthy controls. Neurosci Lett 2002, 324:83-85.

24. Leoni V, Masterman T, Patel P, Meaney S, Diczfalusy U, Bjorkhem I: Side chain oxidized oxysterols in cerebrospinal fluid and the integrity of blood-brain and blood-cerebrospinal fluid barriers. J Lipid Res 2003, 44:793-799.

25. Bonilla E, Tanji K, Hirano M, Vu TH, DiMauro S, Schon EA: Mitochondrial involvement in Alzheimer's disease. Biochim Biophys Acta 1999, 1410:171-182.

26. Butterfield DA, Castegna A, Lauderback CM, Drake J: Evidence that amyloid beta-peptide-induced lipid peroxidation and its sequelae in Alzheimer's disease brain contribute to neuronal death. Neurobiol Aging 2002, 23:655-664.

27. Montine TJ, Markesbery WR, Morrow JD, Roberts $\sqcup J$ 2nd: Cerebrospinal fluid F2-isoprostane levels are increased in Alzheimer's disease. Ann Neurol 1998, 44:410-413.

28. Montine TJ, Beal MF, Cudkowicz ME, O'Donnell H, Margolin RA, McFarland L, Bachrach AF, Zackert WE, Roberts LJ, Morrow JD: Increased CSF F2-isoprostane concentration in probable AD. Neurology 1999, 52:562-565.

29. de Leon MJ, DeSanti S, Zinkowski R, Mehta PD, Pratico D, Segal S, Rusinek H, Li J, Tsui W, Saint Louis LA, Clark CM, Tarshish C, Li Y, Lair L, Javier E, Rich K, Lesbre P, Mosconi L, Reisberg B, Sadowski M, DeBernadis JF, Kerkman DJ, Hampel H, Wahlund LO, Davies P: Longitudinal CSF and MRI biomarkers improve the diagnosis of mild cognitive impairment. Neurobiol Aging 2006, 27:394-401.

30. de Leon MJ, Mosconi L, Li J, De Santi S, Yao Y, Tsui WH, Pirraglia E, Rich K, Javier E, Brys M, Glodzik L, Switalski R, Saint Louis LA, Pratico D: Longitudinal CSF isoprostane and MRI atrophy in the progression to AD. J Neuro/ 2007, 254:1666-1675. 
31. Pratico D, Clark CM, Lee VM, Trojanowski JQ, Rokach J, FitzGerald GA: Increased 8,12-iso-iPF2alpha-VI in Alzheimer's disease: correlation of a noninvasive index of lipid peroxidation with disease severity. Ann Neurol 2000, 48:809-812

32. Pratico D, Clark CM, Liun F, Rokach J, Lee VY, Trojanowski JQ: Increase of brain oxidative stress in mild cognitive impairment: a possible predictor of Alzheimer disease. Arch Neurol 2002, 59:972-976.

33. Feillet-Coudray C, Tourtauchaux R, Niculescu M, Rock E, Tauveron I, Alexandre-Gouabau MC, Rayssiguier Y, Jalenques I, Mazur A: Plasma levels of 8-epiPGF2alpha, an in vivo marker of oxidative stress, are not affected by aging or Alzheimer's disease. Free Radic Biol Med 1999, 27:463-469.

34. Irizarry MC, Yao Y, Hyman BT, Growdon JH, Pratico D: Plasma F2A isoprostane levels in Alzheimer's and Parkinson's disease. Neurodegener Dis 2007, 4:403-405.

35. Flirski M, Sobow T: Biochemical markers and risk factors of Alzheimer's disease. Curr Alzheimer Res 2005, 2:47-64.

36. Teunissen CE, de Vente J, Steinbusch HW, De Bruijn C: Biochemical markers related to Alzheimer's dementia in serum and cerebrospinal fluid. Neurobiol Aging 2002, 23:485-508.

37. Hye A, Lynham S, Thambisetty M, Causevic M, Campbell J, Byers HL, Hooper C, Rijsdijk F, Tabrizi SJ, Banner S, Shaw CE, Foy C, Poppe M, Archer N, Hamilton G, Powell J, Brown RG, Sham P, Ward M, Lovestone S: Proteome-based plasma biomarkers for Alzheimer's disease. Brain 2006, 129:3042-3050.

38. Ueno I, Sakai T, Yamaoka M, Yoshida R, Tsugita A: Analysis of blood plasma proteins in patients with Alzheimer's disease by two-dimensional electrophoresis, sequence homology and immunodetection. Electrophoresis 2000, 21:1832-1845.

39. German DC, Gurnani P, Nandi A, Garner HR, Fisher W, Diaz-Arrastia R, O'Suilleabhain P, Rosenblatt KP: Serum biomarkers for Alzheimer's disease: proteomic discovery. Biomed Pharmacother 2007, 61:383-389.

40. Ray S, Britschgi M, Herbert C, Takeda-Uchimura Y, Boxer A, Blennow K, Friedman LF, Galasko DR, Jutel M, Karydas A, Kaye JA, Leszek J, Miller BL, Minthon L, Quinn JF, Rabinovici GD, Robinson WH, Sabbagh MN, So YT, Sparks DL, Tabaton M, Tinklenberg J, Yesavage JA, Tibshirani R, Wyss-Coray T: Classification and prediction of clinical Alzheimer's diagnosis based on plasma signaling proteins. Nat Med 2007, 13:1359-1362.

41. Doecke JD, Laws SM, Faux NG, Wilson W, Burnham SC, Lam CP, Mondal A, Bedo J, Bush Al, Brown B, De Ruyck K, Ellis KA, Fowler C, Gupta VB, Head R, Macaulay SL, Pertile K, Rowe CC, Rembach A, Rodrigues M, Rumble R, Szoeke C, Taddei K, Taddei T, Trounson B, Ames D, Masters CL, Martins RN; Alzheimer's Disease Neuroimaging Initiative; Australian Imaging Biomarker and Lifestyle Research Group: Blood-based protein biomarkers for diagnosis of Alzheimer disease. Arch Neurol 2012, 69:1318-1325.

42. Hu WT, Holtzman DM, Fagan AM, Shaw LM, Perrin R, Arnold SE, Grossman M, Xiong C, Craig-Schapiro R, Clark CM, Pickering E, Kuhn M, Chen Y, Van Deerlin
VM, McCluskey L, Elman L, Karlawish J, Chen-Plotkin A, Hurtig HI, Siderowf A, Swenson F, Lee VM, Morris JC, Trojanowski JQ, Soares H; Alzheimer's Disease Neuroimaging Initiative: Plasma multianalyte profiling in mild cognitive impairment and Alzheimer disease. Neurology 2012, 79:897-905.

43. Butterfield DA, Boyd-Kimball D, Castegna A: Proteomics in Alzheimer's disease: insights into potential mechanisms of neurodegeneration. J Neurochem 2003, 86:1313-1327.

44. Carrette O, Demalte I, Scherl A, Yalkinoglu O, Corthals G, Burkhard P, Hochstrasser DF, Sanchez JC: A panel of cerebrospinal fluid potential biomarkers for the diagnosis of Alzheimer's disease. Proteomics 2003, 3:1486-1494.

45. Finehout EJ, Franck Z, Choe LH, Relkin N, Lee KH: Cerebrospinal fluid proteomic biomarkers for Alzheimer's disease. Ann Neurol 2007 61:120-129.

46. O'Bryant SE, Xiao G, Barber R, Huebinger R, Wilhelmsen K, Edwards M, GraffRadford N, Doody R, Diaz-Arrastia R: A blood-based screening tool for Alzheimer's disease that spans serum and plasma: findings from TARC and ADNI. PLoS One 2011, 6:e28092.

47. Watt AD, Perez KA, Hung LW: Elucidating the role of metals in Alzheimer's disease through the use of Surface-Enhanced Laser Desorption/lonisation time-of-flight mass spectrometry. Methods Mol Biol 2011, 752:229-240.

48. Zhang R, Barker L, Pinchev D, Marshall J, Rasamoelisolo M, Smith C, Kupchak P, Kireeva I, Ingratta L, Jackowski G: Mining biomarkers in human sera using proteomic tools. Proteomics 2004, 4:244-256.

49. Henkel AW, Muller K, Lewczuk P, Muller T, Marcus K, Kornhuber J, Wiltfang J: Multidimensional plasma protein separation technique for identification of potential Alzheimer's disease plasma biomarkers: a pilot study. J Neural Transm 2012, 119:779-788.

50. Choi J, Malakowsky CA, Talent JM, Conrad CC, Gracy RW: Identification of oxidized plasma proteins in Alzheimer's disease. Biochem Biophys Res Commun 2002, 293:1566-1570.

51. Lopez MF, Mikulskis A, Kuzdzal S, Bennett DA, Kelly J, Golenko E, DiCesare J, Denoyer E, Patton WF, Ediger R, Sapp L, Ziegert T, Lynch C, Kramer S, Whiteley GR, Wall MR, Mannion DP, Della Cioppa G, Rakitan JS, Wolfe GM: Highresolution serum proteomic profiling of Alzheimer disease samples reveals disease-specific, carrier-protein-bound mass signatures. Clin Chem 2005, 51:1946-1954.

doi:10.1186/alzrt185

Cite this article as: Gupta VB, et al:: Multiplex biomarkers in blood.

Alzheimer's Research \& Therapy 2013, 5:31. 